\title{
PENGELOLAAN PASRAMAN DI SD NO.1 DARMASABA DALAM MENINGKATKAN SRADHA DAN BHAKTI SISWA
}

\author{
Oleh \\ Ni Kadek Supadmini dan I Komang Wisnu Budi Wijaya \\ Universitas Hindu Negeri I Gusti Bagus Sugriwa Denpasar \\ ayutrisnadewimaheswari@gmail.com dan wisnu.budiwijaya240191@gmail.com
}

\begin{abstract}
This reaearch aims to identify management patterns in SD No 1 Darmasaba in order to improve student's Sradha and Bhakti. This research is classified into qualitative research. Sources of The research data sources from thePasraman manager, Pasraman activity documents and Hindu literature texts. The data collection method were carried out by observations, interviews and literature. The research instrument that used was observation sheets and interview guidelines. Collected data was analyzed using descriptive analysis techniques. Theresult of the research stated that the Pasramanmanagement in SD No.1 Darmasaba used the POAC pattern, namely Planning, Organizing, Actuation, and Supervision. In implementing this pattern, various parties are involved, for example, Pasraman managers, teachers, school committees, and student's parents.
\end{abstract}

Keywords : Management, Pasraman, Sradha, Bhakti, student

\section{PENDAHULUAN}

Pendidikan merupakan bagian penting dari proses pembangunan nasional yang merupakan investasi dalam pengembangan sumberdaya manusia. Peningkatan sumber daya manusia dalam Rencana Strategis Depdiknas 2005-2025 adalah mewujudkan pendidikan yang mampu membangun insan Indonesia cerdas dan kompetitif, yang berkeadilan, bermutu, dan relevan dengan kebutuhan masyarakat lokal dan global. Selain itu, pemerintah memberikan program pendidikan kepada masyarakat sebagai salah satu upaya pemerintah memenuhi hak warga negaranya yaitu mendapatkan pendidikan (Yasa \& Wijaya, 2020). Indonesia adalah negara yang memberikan jaminan atas hak asasi tersebut, berupa pendidikan bagi setiap warga negaranya. Itulah sebabnya negara memberikan perhatian penuh bagi pendidikan bagi setiap warga negara
Indonesia. Pada pasal 32 ayat 1 dan 2 dalam Undang-Undang Dasar Negara Republik Indonesia Tahun 1945, memberikan jaminan atas hak terhadap pendidikan itu sendiri. pada pasal tersebut lebih spesifik di ayat (1) disebutkan sebagai berikut, "Setiap warga negara berhak mendapatkan pendidikan". Kemudian di ayat (2) pada pasal yang sama dinyatakan "Setiap warga negara wajib mengikuti pendidikan dasar dan pemerintah wajib membiayainya".

Menurut UU No. 20 Tahun 2003 tentang Sistem Pendidikan Nasional (Sisdiknas), di Indonesia terdapat 7 (tujuh) jenis pendidikan yaitu pendidikan umum, akademik, kejuruan, vokasi, khusus, keagamaan dan profesi. Pendidikan keagamaan diatur lebih lanjut dalam Peraturan Pemerintah (PP) No. 55 Tahun 2007 tentang Pendidikan Agama dan Keagamaan. Dalam PP No 55 Tahun 2007

Pengelolaan Pasraman Di SD No.1 Darmasaba Dalam Meningkatkan Sradha Dan Bhakti Siswa 
tentang Pendidikan Agama dan Pendidikan Keagamaan disebutkan bahwa Pendidikan Agama adalah pendidikan yang memberikan pengetahuan dan membentuk sikap, kepribadian, dan keterampilan peserta didik dalam mengamalkan ajaran agamanya, yang dilaksanakan sekurang-kurangnya melalui mata pelajaran/kuliah pada semua jalur, jenjang, dan jenis pendidikan. Dalam PP tersebut juga dituliskan bahwa Pasraman adalah satuan pendidikan keagamaan Hindu pada jalur pendidikan formal dan nonformal. Keberadaan Pasraman semakin dipertegas pula dengan adanya PMA No. 56 Tahun 2014 tentang Pendidikan Keagamaan Hindu yang menyatakan bahwa Pendidikan Keagamaan Hindu adalah jalur pendidikan formal dan nonformal dalam wadah Pasraman. Pasraman formal adalah jalur pendidikan Pasraman yang terstruktur dan berjenjang yang terdiri dari pendidikan dasar, pendidikan menengah dan pendidikan atas. Sedangkan Pasraman nonformal adalah jalur pendidikan di luar Pasraman formal yang dilaksanakan secara terstruktur, dan Pasraman non-formal inilah yang dirasa untuk saat ini cocok untuk dikembangkan melihat keadaan sosial masyarakat dan keberadaan desa pakraman sebagai payung Pasraman non-formal tersebut. Pasraman sebagai bagian dari pendidikan agama dan keagamaan dilakukan sejak jenjang pendidikan dasar (Yasa, Wijaya, Mahendradhani, \& Supadmini, 2020).

Peranan Pasraman sebagai lembaga non formal selama ini dapat menggantikan lembaga formal dalam melestarikan unsurunsur budaya Bali yang sarat dengan nilainilai agama Hindu (Sudika, 2018). Pelestarian kearifan lokal sangat penting untuk menangkal akses negatif dari globalisasi. Adapun konsep ajaran di Pasraman berupa titi, tata, tutur, tentram yang dipraktekkan secara murni dan konsekwen. Titi adalah astiti kepada Ida Sang Hyang Widhi Wasa serta orang tua. Tutur adalah wejangan pandita, para pemimpin pemerintahan dan kepada orang yang lebih mengerti meskipun umurnya lebih muda. Sedangkan tentram merupakan keadaan yang banyak dilandasi oleh kesabaran. Prinsip ajaran spiritual itu dikemas dalam masatwa yang diyakini dapat membentuk karakter anak-anak yang baik. Pasraman sebagai lembaga pendidikan yang bernuansa Hindu kini banyak di Sekolah sekolah. Hal ini terjadi karena adanya kesadaran dan kepedulian dari para tokoh masyarakat, orang tua dan guru bahwa betapa pentingnya pendidikan keagamaan dan budaya disampaikan kepada siswa agar kelak siswa mengetahui agama dan adat istiadat yang patut dilaksanakan pada lingkungan masyarakat, disamping itu kelestarian adat dan budaya juga sangat ditentukan siswa sebagai generasi penerus.

Keberadaan Pasraman sebagai tempat membina sumber daya manusia di sekolah perlu dilakukan, karena sekolah sebagai sebuah organisasi pendidikan dalam menjalankan misinya menggali, memelihara kelestarian kebudayaan Bali yang berlandaskan ajaran agama Hindu sebagai modal dasar pembangunan daerah Bali, faktor sumber daya manusianya merupakan salah satu penentu kuatnya sebuah Negara. Dengan adanya Pasraman Non-formal di masyarakat sesungguhnya menjadi tempat belajar tambahan bagi para siswa, karena pembelajaran utamanya tetap dilaksanakan di sekolah formal. Munculnya gagasan perlu dibentuk Pasraman non-formal didasari oleh alasan pendidikan agama Hindu yang diajarkan di sekolah formal dari tingkat sekolah dasar sampai dengan di perguruan tinggi hanya sepintas saja tanpa ada diberikan pemahaman yang lebih dalam. Pada sekolah formal agama Hindu diajarkan sebagai ilmu

Pengelolaan Pasraman Di SD No.1 Darmasaba Dalam Meningkatkan Sradha Dan Bhakti Siswa 
pengetahuan, sedangkan pendidikan Pasraman menekankan pada disiplin diri, mengembangkan akhlak mulia dan sifat-sifat yang rajin, suka bekerja keras, pengekangan hawa nafsu dan gemar untuk menolong orang lain.

Pengembangan Sradha dan Bhakti melalui Pasraman sebaiknya dilakukan sejak anak berusia sekolah dasar. Hal ini dikarenakan usia siswa di sekolah dasar adalah usia anak yang sedang mengalami perkembangan kognitif, sikap dan psikomotor dengan pesat (I. K. Wi. B. Wijaya, 2018). Salah satu satuan pendidikan yang melaksanakan kegiatan Pasraman adalah SD Negeri No.1 Darmasaba. Sekolah dasar yang berlokasi di desa Darmasaba, Kabupaten Badung ini melaksanakan kegiatan Pasraman secara terjadwal yaitu setiap akhir tahun ajaran dan juga setiap sore hari setelah siswa selesai mengikuti pembelajaran di kelas. Pelaksanakan Pasraman di sekolah itu dilakukan dengan tujuan membentuk siswa dengan mental dan spiritual yang kuat serta sradha dan bhakti yang mantap kepada Ida Sang Hyang Widhi. Berdasarkan hal tersebut maka peneliti tertarik untuk mengkaji pengelolaanPasraman siswa SD Negeri 1 Darmasaba Kabupaten Badung dalam meningkatkan Sradha dan Bhakti.

\section{PEMBAHASAN}

Pasraman merupakan salah satu bentuk wadah dalam proses pendidikan yang secara aktualisasi didasari atas nilai agama Hindu. Dalam terminologi Bahasa Sansekerta, kata Ashram lebih sering muncul sebagai sebuah tempat pertapaan sekaligus guru suci seperti Brahmana melaksanakan tata cara pendidikan dan mendidik murid mereka dalam disiplin spiritual yang sangat ketat. Aturan ini secara nyata membedakan pendidikan yang terdapat di pertapaan dengan pendidikan yang ada di lembaga formal lainnya.

Pasraman yang terdapat di SD Negeri 1 Darmasaba adalah Pasraman yang secara fundamental mengikuti dasar ajaran agama Hindu. Namun tempat pelaksanaannya yang berada di lingkungan sekolah. Secara otomatis, sisyaPasraman adalah murid di lingkungan sekolah SD Negeri 1 Darmasaba yang beragama Hindu. Secara pengelolaan, tentu akan berbeda dengan Pasraman yang berada di luar lembaga formal di masyarakat. Perbandingan ini perlu dilakukan, agar dapat mengetahui bahwa meskipun terdapat perbedaan pola pengelolaan Pasraman, namun secara fundamental, ajaran agama Hindu yang bersumber dari kitab suci Veda, tetap diberikan secara sistematis.

Pengelolaan pasraman tidak hanya melibatkan pihak sekolah saja melainkan melibatkan keluarga dan masyarakat. Hal itu dikarenakan proses pendidikan khususnya di pasraman akan berjalan lancar jika adanya sinergi antara keluarga, sekolah dan masyarakat (Wijaya, Darmayanti, \& Muliani, 2020). Pola pengelolaan Pasraman di SD Negeri 1 Darmasaba dilaksanakan dengan mempergunakan pola POAC (Planning, Organizing, Actuating and Controlling). Penjelasan masing-masing adalah sebagai berikut :

\subsection{Planning}

Planning ini merupakan sebuah perencanaan dasar dan mencakup secara keseluruhan kegiatan yang akan dilaksanakan Pasraman SD Negeri 1 Darmasaba. Dalam Pasraman SD Negeri 1 Darmasaba, perencanaan tersebut meliputi hal sebagai berikut : 1) Perencanaan mengenai upanayana (penyucian diri sebelum sisya atau murid yang mengikuti Pasraman belajar mengenai ajaran agama Hindu), 2) Perencanaan mengenai materi ajar yang akan diberikan kepada sisya

Pengelolaan Pasraman Di SD No.1 Darmasaba Dalam Meningkatkan Sradha Dan Bhakti Siswa 
atau murid Pasraman di SD Negeri 1 Darmasaba dan 3) Perencanaan tentang evaluasi materi Pasraman yang sudah diberikan kepada sisya atau anak didik.

Komite sekolah dilibatkan dalam proses perencanaan Pasraman. Secara formal, Pasraman yang dilaksanakan di SD Negeri 1 Darmasaba ini, berada di luar jam pelajaran secara resmi. Berdasarkan hal tersebut, wajib mengikutsertakan komite sekolah untuk setiap perencanaan yang akan dibuat. Peranan komite sekolah secara berkesinambungan memang diperlukan untuk sebuah tindakan nyata keikutsertaan masyarakat dalam memajukan dunia pendidikan. Terkait dengan rencana Pasraman tersebut, maka komite dilibatkan untuk menyusun bersama materi Pasraman yang akan diberikan kepada siswa sebagai bagian dari penguatan agama Hindu. Meteri Pasraman yang masuk dalam perencanaan pengelolaan ini, adalah meliputi hal dasar yang wajib diketahi sebagai umat Hindu di Bali. Kemudian keterampilan yang sebisa mungkin wajib dimiliki siswa Hindu. Adapun materi yang masuk dalam perencanaan tersebut adalah : 1) Materi tentang Tri Sandhya dan Panca Kramaning Sembah, 2) Materi Ketuhanan dalam agama Hindu di Bali, 3) Materi Dharmagita atau nyanyian suci dalam ritual keagamaan Hindu di Bali, 4) Keterampilan putera mengenai sarana upakara yajna, 5) Keterampilan puteri dalam membuat sarana upakara yajna dan 6) Materi tentang Yoga.

Keseluruhan tersebut merupakan rencana untuk materi yang akan diberikan dalam Pasraman. Seluruhnya baik Tri Sandhya dan Panca Kramaning Sembah, kemudian materi ketuhanan, Yoga, materi dharmagita dan materi tentang keterampilan putera dan puteri dalam membuat upakara yajna, semuanya dilandasi atas kearifan agama Hindu yang berlaku di Bali.
Perencanaan seperti ini dibuat untuk memberikan penguatan keyakinan (Sraddha) dalam agama Hindu di Bali dan tidak tercabut dari akar kebudayaannya. Tujuan tersebut sebenarnya merupakan pengejawantahan dari Nawacitta oleh pemerintah, dimana masyarakat Indonesia, harus berkepribadian dalam budaya sendiri.

Perencanaan ini penting dibuat agar tidak kehilangan esensi dalam penerapan materi pada Pasraman yang diselenggarakan. Pendidikan yang mengedepankan kearifan lokal, akan membuat anak didik semakin teguh akan jati dirinya (Slameto, 2012). Kondisi ini sebenarnya membentuk siswa Hindu memiliki berkepribadian dalam budaya. Maka dengan demikian dapat dinyatakan bahwa perencanaan dalam pengelolaan Pasraman SD Negeri 1 Darmasaba ini, melibatkan komite sekolah, kemudian meteri yang akan diberikan adalah materi yang memperkuat keyakinan (Sraddha) siswa berlandaskan kearifan lokal masyarakat Hindu di Bali.

\subsection{Organizing}

Organizing dimaksudkan agar pengelolaan Pasraman menjadi lebih proporsional dan tidak melebar jauh dari tujuan yang ditetapkan. Dalam Pasraman SD Negeri 1 Darmasaba Pasraman akan dikelola dengan sistem organisasi layaknya Pasraman yang lain. Berikut bagannya. 


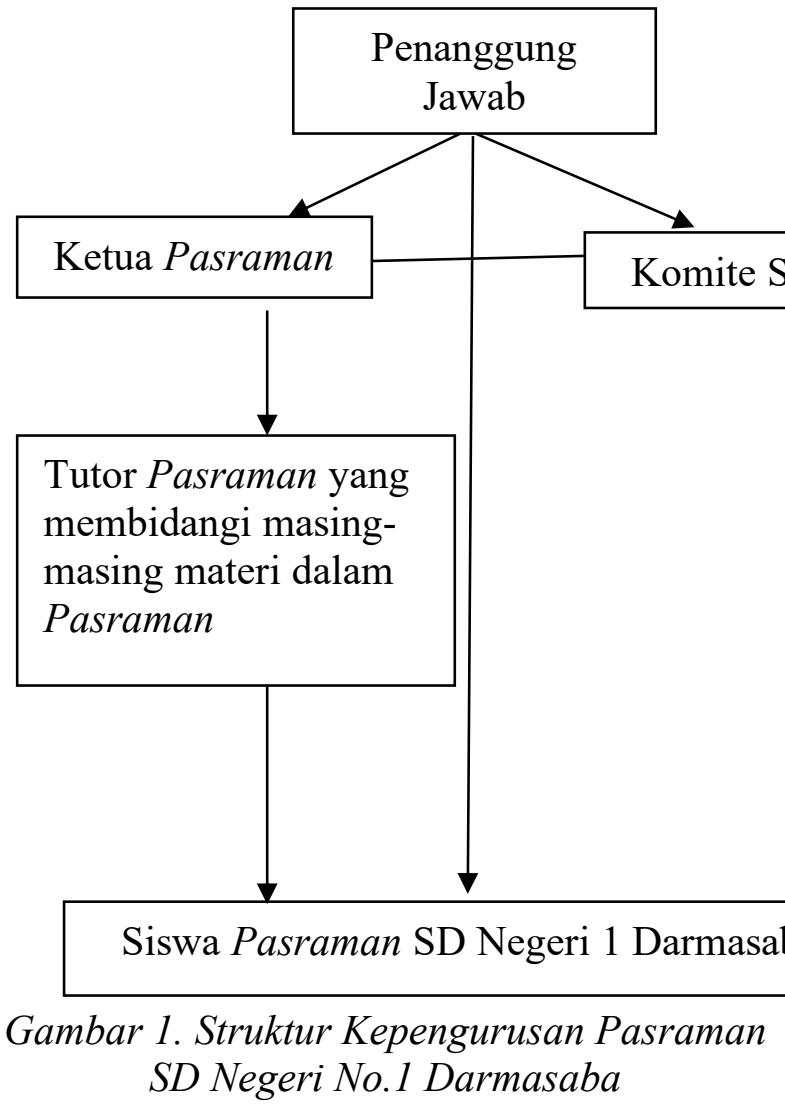

Penanggung jawab Pasraman adalah personal yang memiliki tanggung jawab atas seluruh pelaksanaan Pasraman. Baik dalam ranah keberadaan siswa Pasraman, ataupun tempat dimana Pasraman tersebut dilaksanakan. Artinya penanggung jawab ini adalah kepala sekolah SD Negeri 1 Darmasaba. Hal tersebut difaktori oleh beberapa hal, yakni.

1. Tempat dilaksanakannya Pasraman adalah di lingkungan SD Negeri 1 Darmasaba.

2. Siswa Pasraman merupakan anak didik langsung dari SD Negeri 1 Darmasaba yang secara notabena tercatat secara resmi dan formal dalam SD Negeri 1 Darmasaba
3. Guru yang menjadi tutor dalam Pasraman, merupakan guru yang bertugas di SD Negeri 1 Darmasaba.

Faktor tersebut memberikan kuasa penuh kepada kepala sekolah, sebagai kolah sung jawab atas pelaksanaan r usruman di SD Negeri 1 Darmasaba. Dengan demikian seluruh hal yang berkaitan dengan keberadaan guru, siswa dan tempat pelaksanaan Pasraman tersebut, dapat diawasi dengan baik. kemudian komite sekolah menjadi bagian penting dalam usaha pengelolaan Pasraman secara organisasi. Dalam bagan di atas, komite sekolah tidak menjadi tutor Pasraman. Artinya komite sekolah hanya ikut memberikan saran, pendapat atau masukan tentang materi Pasraman dan tidak ikut menjadi pengajar di Pasraman.

Komite sekolah juga tidak boleh gintervensi jalannya Pasraman SD Negeri 1 Darmasaba dan memberikan penilaian terhadap siswa secara tersistematis dalam upaya pemberikan materi dalam Pasraman tersebut. Masalah waktu pelaksanaan Pasraman, maka komite sekolah juga tidak berhak ikut campur dalam menentukan waktu dan durasi belajar anak didik di Pasraman SD Negeri 1 Darmasaba. Hal tersebut sepenuhnya menjadi hak tutor Pasraman dan penanggung jawab Pasraman.

Guru yang mengampu materi Pasraman, ditentukan berdasarkan atas kemampuan dari guru tersebut dalam penguasaan materi. Maka materi akan semakin mudah untuk ditransfer kepada siswa Pasraman dengan melibatkan guru yang memiliki kompetensi. Seluruh siswa dikelola dengan konsep gurukula. Artinya belajar dengan nuansa keluarga.

Gurukula yang dimaksudkan adalah bahwa Pasraman SD Negeri 1 Darmasaba dalam pengorganisasian pengelolaan

Pengelolaan Pasraman Di SD No.1 Darmasaba Dalam Meningkatkan Sradha Dan Bhakti Siswa

Universitas Hindu Negeri I Gusti Bagus Sugriwa Denpasar
Ni Kadek Supadmini dan I Komang Wisnu Budi Wijaya 
Pasramannya, tidak kaku seperti pendidikan formal. Namun lebih humanis seperti keluarga, guru atau tutor Pasraman layaknya orang tua, dan siswa Pasraman seperti anak sendiri. Mentransformasikan nilai pendidikan agama Hindu, memang lebih mudah dengan jalan demikian.

\subsection{Actuating}

Actuating atau pelaksanaan Pasraman

SD Negeri 1 Darmasaba secara berkelanjutan, mengikuti pola yang sudah ditetapkan bersama komite sekolah. Dengan demikian secara faktual, pelaksanaan Pasraman tidak akan terlepas dari materi yang ditetapkan dan tujuan yang ingin dicapai. Pasraman SD Negeri 1 Darmasaba memiliki tujuan "Membentuk kepribadian siswa yang religius, cerdas dan berbudi pekerti luhur" menjadi acuan pelaksanaan Pasraman tersebut. Pelaksanaan Pasraman SD Negeri 1 Darmasaba dilaksanakan oleh tutor Pasraman yang merupakan guru SD Negeri Darmasaba serta diikuti oleh siswa SD Negeri 1 Darmasaba. Dalam pelaksanaannya diberikan materi berupa Tri sandhya, Panca Kramaning Sembah, Yoga, Dharmagita, Ketuhanan dan Keterampilan Putera-puteri.

Dalam Pasraman SD Negeri 1 Darmasaba ini, materi Puja Tri Sandhya yang diberikan oleh tutor, lengkap dengan terjemahannya. Artinya, siswa tidak hanya diberikan materi untuk menghafal mantra dalam setiap bait dari Puja Tri Sandhya, melainkan juga akan diberikan terjemahan dari setiap bait dalam Puja Tri Sandhya tersebut. Tujuannya adalah, ketika siswa mengetahui makna dan arti dalam setiap mantra tersebut, dengan mudah siswa dapat menghayati setiap maksud dan tujuan dari mantra yang diucapkan atau dirafalkan.

Pemahaman akan Puja Tri Sandhya memang tidak dapat hanya diberikan lewat hafalan semata. Namun juga penekanan akan makna dari masing-masing mantra tersebut. secara keseluruhan, siswa yang mengikuti Pasraman di SD Negeri 1 Darmasaba, menghafalkan dengan jalan literal. Artinya dibimbing oleh guru atau tutor Pasraman agar setiap mantra yang diucapkan, akan tepat dalam mengucapannya. Sebab mantra itu sendiri, akan berubah artinya, ketika pengucapannya berubah.

Materi selanjutnya adalah Panca Kramaning Sembah. Secara umum hal ini dilaksanakan dalam persembahyangan Hindu di Bali, akan tetapi perlu sebuah penguatan materi Panca Kramaning Sembah, kepada siswa agar pemahaman serta kemampuannya meningkat. Urutan dalam pelaksanaan persembahyangan menjadi materi pokok yang dikemas dalam Puja Tri sandhya dan Panca Kramaning Sembah. Secara tekstual, siswa diharapkan dapat membaca dan menghafalkan seluruh mantra tersebut dengan baik dan benar. Kemudian secara kontekstual, maka siswa diharapkan mampu memahami dan mengerti mengenai makna dan tujuan dari mantra tersebut.

Materi tentang Ketuhanan yang ditanamkan dalam Pasraman SD Negeri 1 Darmasaba adalah berkaitan konsep Cadu Sakti. Konsep Cadu Sakti secara universal merupakan cara untuk menjelaskan kemahakuasaan Tuhan kepada siswa dengan mudah dan sederhana agar dapat dimengerti dengan baik. Konsep ketuhanan ini diberikan kepada anak didik atau siswa di Pasraman SD Negeri 1 Darmasaba untuk menghayati kemahakuasaan Tuhan. Konsep ini adalah kosep yang paling mudah dipahami oleh anak didik, dari pada konsep ketuhanan yang lainnya.

Pada Pasraman SD Negeri 1 Darmasaba, materi dharma gita diberikan sebagai upaya untuk ikut mewariskan bagian

Pengelolaan Pasraman Di SD No.1 Darmasaba Dalam Meningkatkan Sradha Dan Bhakti Siswa 
GUNA WIDYA : JURNAL PENDIDIKAN HINDU JURUSAN PENDIDIKAN AGAMA

FAKULTAS DHARMA ACARYA

UNIVERSITAS HINDU NEGERI I GUSTI BAGUS

SUGRIWA DENPASAR
VOLUME 8 NOMOR 1 MARET 2021

ISSN : 2355-5696 (CETAK)

ISSN : 2655-0156 (ONLINE)

http://ejournal.ihdn.ac.id/index.php/GW penting dalam ritual Hindu di Bali. Adapun materi dharmagitanya adalah sebagai berikut.

1. Sekar Alit. Yakni pupuh yang memiliki konten berkaitan dengan yajna atau ritual Hindu di Bali.

2. Sekar Madya. Berupa kidung yang memang lumrah dipergunakan dalam mengiringi upacara Hindu di Bali.

Keterampilan putera dan puteri merupakan materi Pasraman yang di actuating dengan jalan praktek langsung. Siswa Pasraman SD Negeri 1 Darmasaba secara langsung mengerjakan setiap upakara yang diberikan contoh oleh guru atau tutor Pasraman. Diberikannya materi ini adalah sebagai penguatan muatan lokal di Bali, bahwa seluruh rangakaian upacara Hindu di Bali, memerlukan perlengkapan ritual. Adapun keterampilan putera yang diberikan dalam Pasraman SD Negeri 1 Darmasaba yaitu : 1) Klakat Banten, 2) Klakat Caru, 3)Sengkui serta Klabang Maikuh, 4) Katik Sate Galungan dan 5) Klangsah/Klabang.Pasraman SD Negeri 1 Darmasaba memberikan materi keterampilan puteri berupa mejejahitan dan tandingan. Adapun materi tersebut sebagai berikut: 1) Canang, 2) Segehan dan 3) Jejaitan Soda/ajuman dan 4) Pejati. Dalam kegiatan actuating, peran guru tidak dapat diabaikan yaitu sebagai sebagai perancang pembelajaran, pengelola pembelajaran, pengarah pembelajaran, evaluator dan konselor (Uno, 2007)

\subsection{Controlling}

Controlling merupakan bentuk pengawasan dari seluruh bentuk kegiatan Pasraman. Pengawasan ini dilaksanakan dengan jalan yang melibatkan seluruh komponen baik dari sekolah dan komite sekolah. Secara hirarki, komite sekolah memang ikut merencanakan dan memberikan masukan mengenai Pasraman sekolah, dan memberikan saran mengenai materi yang diberikan kepada siswa Pasraman SD Negeri 1 Darmasaba. Akan tetapi, komite sekolah tidak berhak menilai siswa dalam melaksanakan Pasraman, artinya komite sekolah tidak memiliki kewenangan di dalam menentukan pakaha siswa Pasraman berhasil dan tidaknya menyerap seluruh materi yang diberikan. Controlling yang melibatkan komite sekolah, adalah memberikan ruang untuk ikut memberikan masukan dan kontrol, apabila di dalam pelaksanaannya secara keseluruhan menyimpang dari konsep yang sudah disepakati.

\section{SIMPULAN}

Berdasarkan uraian pembahasan dapat disimpulkan bahwa pola pengelolaan Pasraman SD Negeri 1 Darmasaba dikelola dengan pola POAC yaitu Planning (Perencanaan), Organizing (Organisasi), Actuating (Pelaksanaan) dan Controlling (Pengawasan). Perencanaan yang melibatkan seluruh komponen, termasuk Komite Sekolah. Kemudian pengorganisasian dilaksanakan dengan melibatkan guru yang bertugas di SD Negeri 1 Darmasaba. PelaksanaanPasraman diaplikasikan dengan materi local genius Hindu di Bali, serta pengawasan dilaksanakan agar seluruh pelaksanaan tidak menyimpang dari rencana yang sudah ditetapkan.

\section{DAFTAR PUSTAKA}

Peraturan Pemerintah (PP) No. 55 Tahun 2007 tentang Pendidikan Agama dan Keagamaan

Sudika, I Wayan, 2018. Peranan Pasraman Dalam Mewujudkan Kehidupan Masyarakat yang Harmonis. Maha Widya Duta STHAN Mpu Kuturan Singaraja.

Pengelolaan Pasraman Di SD No.1 Darmasaba Dalam Meningkatkan Sradha Dan Bhakti Siswa 
UU RI No.20, Tahun 2003, Tentang Sistem

Pendidikan Rasional, 2003. Jakarta. Sinar Grafika. Indonesia.

Uno, H. B. (2007). Profesi Kependidikan. Jakarta: Bumi Aksara.

Wijaya, I. K. W. B., Darmayanti, N. W. S., \& Muliani, N. M. (2020). PENGEMBANGAN

KETERAMPILAN HIDUP DAN KARIR SISWA DALAM RANGKA PENINGKATAN MUTU LULUSAN SEKOLAH DASAR. Jurnal Penjaminan Mutu, 6(2), 171-181.

Wijaya, I. K. Wi. B. (2018). MENGEMBANGKAN KECERDASAN MAJEMUK SISWA SEKOLAH DASAR (SD) MELALUI PEMBELAJARAN IPA UNTUK MENINGKATKAN MUTU LULUSAN SEKOLAH DASAR. Jurnal Penjaminan Mutu, 4, 147-154.

Yasa, I. M. W., \& Wijaya, I. K. W. B. (2020). Kompetensi Guru Agama Hindu Yang Belum Bersertifikat Pendidik. Jurnal Purwadita, 4(2), 181-186.

Yasa, I. M. W., Wijaya, I. K. W. B., Mahendradhani, I. G. A. A. R., \& Supadmini, N. K. (2020). Motivasi Berprestasi Guru Agama Hindu Jenjang SMP Yang Sudah Bersertifikat Pendidik. Jurnal Cetta, 3(3), 463-471. 